


\title{
Gastric Neuroendocrine Neoplasm : WHO Classification 2019
}

\section{Eka Putra Pratama, Suly Auline Rusminan}

Anatomical Pathology Department, Faculty of Medicine Universitas Sriwijaya, Palembang, Indonesia

\section{A R T I C L E I N F O}

\section{Keywords:}

Neoplasma Neuroendokrin Gaster Klasifikasi Who 2019

Tumor Neuroendokrin Gaster

Karsinoma Neuroendokrin Gaster

Sel Neuroendokrin Gaster

\section{Corresponding author: \\ Eka Putra Pratama \\ E-mail address: : \\ ressandoz@yahoo.com}

All authors have reviewed and approved the final version of the manuscript.

\begin{abstract}
A B S T R A C T
Neuroendocrine neoplasm (NEN) of gastric is a term that includes all tumour types with neuroendocrine differentiation of gastric, well differentiated or poorly differentiated tumour. NEN is a new term in 2019 World Health Organization (WHO) classification of digestive system tumours. In WHO 2019 had many updates, one of them is neuroendocrine tumours (NET) grade 3 have been included in tumour category of well differentiated tumour or NET. Previously, NET G3 in WHO 2010 are included as poorly differentiated tumour or neuroendocrine carcinoma (NEC). This neoplasm is genetically well differentiated and because of that, WHO 2019 classification included them as a well differentiated tumour. For NEC, WHO 2019 subdivided them as NEC with small cells (SCNEC) and NEC with large cells (LCNEC). In WHO 2010, mixed type neuroendocrine neoplasms with other components of carcinoma are called mixed adenoneuroendocrine carcinoma (MANEC). But, not all of non-neuroendocrine components are adenocarcinoma and it is possible that one of the components in not carcinoma. Because of that, in WHO 2019 the term has been changed to mixed neuroendocrine-non neuroendocrine neoplasm (MiNEN).
\end{abstract}

https://doi.org/10.37275/JRP.v1i2.7

\section{Introduction}

Neuroendocrine neoplasms (NEN) can occur in all epithelial organs of the body with various etiologies, clinical features, morphology, genetic findings and prognosis. Previously, NEN at various anatomical locations had been classified separately and although the classification system was different, these tumors had several features in common. In 2018, WHO published a uniform classification for all neuroendocrine neoplasms based on the conference consensus in November 2017. This classification distinguishes between well-differentiated neuroendocrine tumors (NET) and poorly differentiated neuroendocrine carcinomas (NEC). The morphological classification which divides NEN into NET and NEC is supported by evidence of differences in genetic, clinical, epidemiological, histological and prognostic differences. ${ }^{1}$
Low-grade gastric neuroendocrine neoplasms or gastro-endocrine tumors (GNET) are rare tumors, occurring in only 1 to 2 cases per 1 million people per year and accounting for $8.7 \%$ of all gastrointestinal neuroendocrine tumors. GNET is classified into several subtypes based on their pathogenesis and histomorphological characteristics. These types differ in their biology and prognosis, ranging from benign to malignant biology with a very poor prognosis. 2,3

High grade gastric neuroendocrine neoplasm or neuroendocrine carcinoma of the stomach is also a rare tumor, accounting for as much as $1 \%$ of all gastric cancers. Gastric neuroendocrine carcinoma is an aggressive tumor and has a very poor prognosis. Gastric neuroendocrine carcinoma is classified as a G3 neuroendocrine tumor in the 2010 World Health Organization (WHO) classification.1.4.5.6 
Based on the background previously explained that neuroendocrine neoplasms in the stomach are rare lesions so that understanding of these neoplasms is still lacking and there are also many neuroendocrine tumor subtypes in the stomach. Therefore, this reference will discuss the morphology of neuroendocrine neoplasms in specific gastric organs, as well as changes in the classification of gastric neuroendocrine neoplasms in the 2019 WHO classification in order to understand current changes and to update knowledge about gastric neuroendocrine neoplasms.

\section{Physiology and types of gastric neuroendocrine cells}

Neuroendocrine cells can act as endocrine, autocrine and paracrine functions. They also have neurosecretoric granules at the ultrastructural level and some indicate the presence of cells with neuronshaped processes. The neuroendocrine cells release secretory granules into the circulation to produce endocrine effects. Neurocrine effects are generated when neuroendocrine cells stimulate afferent nerves. The paracrine effect occurs through expansion in the basal portion of neuroendocrine cells that interact with other neuroendocrine cells or epithelial cells. ${ }^{7,8}$

Gastric neuroendocrine cells are usually scattered along the epithelial cells and gastric glands, but can also be found in the lamina propia. The neuroendocrine cells of the oxytic mucosa are usually located in the glands, especially in the basal part. The numbers vary, but are generally less than 10-20 cells per gland. Neuroendocrine cells in the gastric pyloric mucosa are usually located in the neck region slightly below the foveola. In the pyloric mucosa, the number of cells is more between 20 and 50 cells per crypt. ${ }^{8}$

$\mathrm{G}$ cells are cells that secrete gastrin and are round, oval, large and have solid cytoplasmic granules. They are predominantly located on the neck of the glands in the antrum. G cells number about 1 to 4 cells per gland. G cells are easily identified by the immunohistochemistry of gastrin, synaptophycin and CgA. G cells produce gastrin, which increases the secretion of acids and pepsinogens, gastric motility and proliferation of gastric oxytic mucosa. ${ }^{8}$

EC cells are scattered rarely on the neck of the gland, but are numerous in the lower half of the gland. EC cells are usually numerous in the area of the intestinal metaplasia. EC cells synthesize and release serotonin. EC cells have special microvilli projections into the lumen, so that they function as sensors for the lumen contents of the digestive tract. EC cells are usually marked with basolateral granules of bright red color, although some EC cells may appear clear. The cytoplasm consists of a large number of secretory granules. ${ }^{8}$

D cells secrete somatostatin and are uniformly distributed along the antrum and oxytic mucosa. About $20 \%$ of gastric D cells have axon-shaped basal cytoplasmic processes with terminal expansion that provide paracrine function to D cells. Most D cells act as receptors that interact with luminal content. A feedback mechanism exists, whereby intraluminal acid stimulates secretion of somatostatin. Somatostatin prevents stomach acid, gastrin, intrinsic factor and acetylcholine secretion. D cells can be seen with somatostatin staining. 8

ECL cells have a lateral processus that extends to the surface of the parietal cells, thus causing ECL cells to function as paracrine. ECL cells are pyramidal and closed, with a broad basal portion. ECL cells are only found in the oxytic mucosa where they are the dominant neuroendocrine cells, about $40-45 \%$ of the mucosal oxytic neuroendocrine cells. The ECL cells are randomly scattered along the lower and middle third of the gland. ECL cells have gastrin receptors, which play a role in histamine secretion and ECL cell growth. 8,9

P / D1 cells are polygonal or bottle-shaped in the oxytic mucosa. These cells are large compared to the surrounding cells. Ghrelin is a peptide produced by as many as $20 \%$ of P / D1 cells. Ghrelin can stimulate the release of growth hormone, increase appetite, stimulate gastric contractions and modulate sleep. P / D1 cells can be identified by immunohistochemistry antisera ghrelin. ${ }^{8}$ 


\section{WHO classification of gastric neuroendocrine neoplasms}

The classification of neuroendocrine tumors is presented in a separate chapter in this edition of the book (in the introduction section). The International Agency for Research on Cancer (IARC) in November 2017 has proposed differences in NET and NEC at all locations of the organs where these tumors originated. NEN can be divided into NET and NEC, based on their molecular differences. 5,10,11

In the 2019 WHO classification, a well-differentiated NET can become a high-grade NET (G3 at the 2019 WHO degree), defined as having a mitotic rate of $>20$ per $2 \mathrm{~mm}^{2}$ or Ki-67 $>20 \%$, but these neoplasms remain differentiated both genetically and differently. with poorly differentiated NEC. Therefore, the current WHO classification makes it three degrees (G1, G2 and G3) for NET. NECs are no longer graded, because they are considered high-grade by definition, but are still separated into large or small cell types. Mixed neuroendocrine-non-neuroendocrine

(MiNEN) neoplasm is a mixed epithelial neoplasm in which a neuroendocrine component is combined with a nonneuroendocrine component. Previously in WHO 2010, this mixed-type neoplasm was classified as mixed adenoneuroendocrine carcinoma (MANEC). However, not all non-neuroendocrine components are adenocarcinoma and it is possible that one of the components is not carcinoma, so at WHO 2019 it has been renamed to MiNEN. MiNEN was considered a conceptual category compared with specific diagnoses

(Table 1). ${ }^{5,11}$

\section{Gastric neuroendocrine tumor}

NET is divided into three degrees based on mitotic activity and their Ki-67 proliferative index which has previously been shown in table 1. NET can also be divided into several subtypes based on their location. ECL NET originates from the corpus or fundus. NET D cells and G cells derived from the antrum and NET EC cells can be derived from both (Table 2). ${ }^{11}$

\section{ECL cell neuroendocrine tumors}

ECL cell neuroendocrine tumors are divided into three types with different clinical features (Table 3). Types 1 and 2 are caused by the influence of hypergastrinemia. Type 1 is associated with secondary (compensatory) hypergastrinemia due to hypochlorhydria from autoimmune gastritis. Type 2 is associated with primary hypergastrinemia, for example due to Zollinger-Ellison syndrome (ZES) or MEN1 syndrome. The process that occurs is the overproduction of gastrin in ECL cells, which causes the proliferation of this type of cell. Gastric neuroendocrine tumor type 3 can show the proliferation of various cell types including EC and ECL cells. 8

ECL cell neuroendocrine tumors are mostly detected incidentally during evaluation by endoscopy. On endoscopic examination of GNET ECL cells in the early stages, there is usually a mucosal area that is reddish, smooth and a mass of small polyps that are raised red, multiple. Gastric neuroendocrine tumors type 3 are usually larger in size, 1,8,12

The macroscopic appearance of ECL cell NET includes well-defined, smooth, chewy consistency, reddish, non-encapsulated lesions. The cut shows a smooth, homogeneous image with a chewy consistency. Vascularity can lead to a darker color with focal-focal bleeding (Figure 1). Mucosal ulceration and necrosis can be seen in advanced cases and is a sign of a more aggressive tumor. Neuroendocrine tumors of ECL type 1 cells are the less aggressive GNETs and most are less than $1.5 \mathrm{~cm}$ in diameter. NET type 2 ECL cells have a diameter greater than $1.5 \mathrm{~cm}$ and in type $3 \mathrm{NET}$ a diameter of more than $2 \mathrm{~cm}$. 7,8,12

ECL cell neuroendocrine tumors usually show a microlobular and trabecular pattern without necrosis. They consist of well-differentiated cells with a broad eosinophilic cytoplasm, a spherical, monomorphic nucleus, salt-and-pepper chromatin and less prominent nuclei. Most NET types 1 and 2 are G1 or G2. Mucosal NET type 1 ECL cells are usually atrophic, with intestinal and pseudopiloric metaplasia, and there may be ECL cell hyperplasia and dysplastic changes. The mucosal NET ECL cells exhibit various types of 
ECL cell hyperplasia and dysplasia, usually without atrophy. (Figure 2). 6,11

Neuroendocrine tumors of type 3 ECL cells can range from G1 to G3 and this type can invade deeper gastric walls, having higher mitotic activity. Histologically, this tumor type is characterized by a solid or diffuse pattern, which consists of spindle or round cells. Focal necrosis is common (Figure 3). 6,11

Gastric neuroendocrine tumors were positive for common neuroendocrine markers such as synaptophycin and CgA (Figure 4). In addition, all NET ECL cells were positive for vesicular monoamine transporter 2 (VMAT2) and somatostatin receptor 2 (SSTR2A). Immunohistochemistry such as SSTR2 cannot be seen on NET G3. Neuroendocrine tumors of ECL type 1 and 2 cells were strongly positive for CgA immunohistochemistry, whereas neuroendocrine tumors type 3 were usually negative for CgA.6,11 In G1 the tumors usually showed a Ki-67 proliferation index $<2 \%$. G2 with a Ki-67 proliferation index of $3-20 \%$. G3 with a Ki-67 proliferation index of $>20 \%$ (Figure 5). The Ki-67 proliferation index is determined by counting the number of neoplastic cells labeled Ki-67 as a percentage of 500-2000 neoplastic cells.

The prognosis for neuroendocrine tumor type 1 ECL cells is excellent and type 3 is worse. Type 2 has an intermedia prognosis, depending on the MEN1 abnormality. Neuroendocrine tumors of ECL type 1 cells rarely metastasize. They almost never cause a patient's death. In neuroendocrine tumors ECL type 2 cells with ZES are more likely to metastasize than type 1 , and usually to the liver in about $10 \%$ of tumors. In about $30 \%$ of tumors can metastasize to local lymph nodes. Neuroendocrine tumor type 3 shows a more aggressive nature and often metastasizes. The 5-year survability rate in this patient is $<50 \% \cdot 6,8,11,14$

\section{G cell neuroendocrine tumors}

G-cell neuroendocrine tumors of the stomach are extremely rare, 95\% of which occur in "triangle gastrinomas". It is usually superior to the common bile duct, inferior to the duodenum, and medially to the pancreas. The term "gastric gastrinoma" is only used in cases that are functional and not in tumors expressing gastrin in the absence of clinical manifestations. ${ }^{8,11,15}$ Approximately $75 \%$ of cases of G-cell NET are sporadic tumors, of which $25 \%$ are associated with the MEN1 gene. In patients with the MEN1 gene mutation with duodenal gastrinoma, G-cell hyperplasia of the gastric antrum usually occurs, which is associated with the presence of $\mathrm{H}$. pylori gastritis and long-term use of proton pump inhibitors (PPIs). In this case it is often followed by hyperplasia of ECL cells. ${ }^{13}$

G-cell neuroendocrine tumors in the stomach are usually found incidentally during endoscopic examination. On endoscopic examination, the tumor was a polypoid with a diameter of 0.2 to $20 \mathrm{~cm}$, with an average size of $<1 \mathrm{~cm}$. The surface of the lesions is usually smooth and may experience central erosions or deep ulcers (Figure 6). Normal serum gastrin levels $<100 \mathrm{pg} / \mathrm{ml}$, however, in gastrinoma patients, gastrin levels can increase to $137-1550 \mathrm{pg} / \mathrm{ml}$. 15,16,17

Neuroendocrine G-cell tumors typically show a thin trabecular pattern and a giriformis (Figure 7). Uniform tumor cells with narrow cytoplasm. ${ }^{11}$ Neuroendocrine G-cell tumors are indistinguishable from other NETs. The diagnosis can only be made by immunoreactivity against gastrin in the majority of cells. Ki-67 proliferation depending on the degree of the tumor. ${ }^{8}$

$\mathrm{G}$ cell neuroendocrine tumors are slow growing tumors. Markers that can predict tumor aggressiveness and metastasis include tumor size and tumor invasion through the submucosa. Patients with ZES have a tendency to metastasize and usually metastasize to the liver. The 10-year survability rate was 94\% .8

\section{EC cell neuroendocrine tumors}

This tumor subtype is very rare in the stomach and is usually non-functional, but there may also be symptoms of classic carcinoid syndrome. Not much is known and studied about neuroendocrine tumors of EC cells in the stomach, because these cells are difficult to identify among other neuroendocrine cells scattered in the stomach. Neuroendocrine tumors of gastric EC cells have round nests with peripheral palisading (Figure 8). Uniform tumor cells with 
eosinophilic cytoplasm. NET positive gastric EC cells for serotonin, SSTR2A and CDX. ${ }^{11}$

\section{D cell neuroendocrine tumors}

Neuroendocrine D-cell tumors of the stomach are very rare tumors consisting of well-differentiated monomorphic cells that are positive for somatostatin. The ages of patients with these tumors range from 29 to 83. Most tumors of this subtype are caused by mutations in the $N F 1$ gene and are common in patients with neurofibromatosis and pheochromocytoma. Macroscopically, these tumors appear well-defined, gray-white to yellowish in color, can ulcerate and bleed with an average diameter of 5-6 cm. On histopathological examination, this tumor has the same picture as other types of NET in the form of a trabecular pattern with round nucleated cells, monomorphic, salt-and-pepper chromatin and less prominent nuclei (Figure 9). Mitosis depends on the degree of the tumor. Staining with somatostatin showed intense immunoreactivity in a large proportion of the tumor cell population. 8,11

\section{Gastric neuroendocrine carcinoma}

Gastric neuroendocrine carcinoma is a rare tumor, accounting for less than $10 \%$ of all gastric NEN. Small cell type gastric neuroendocrine carcinoma is more common in men than in women. The mean age of the occurrence of this type of tumor is 63 years. Large cell type gastric neuroendocrine carcinoma was four times more common than small cell type. Gastric neuroendocrine carcinoma has two subtypes, namely small cell type NEC (SCNEC) and large cell type NEC (LCNEC) (Table 4). ${ }^{11}$

Neuroendocrine carcinoma

and adenoneuroendocrine mixed carcinoma have the same etiology as gastric adenocarcinoma, including smoking, high salt intake, fatty foods and $H$. pylori infection. Gastric NEC also shows several chromosomal abnormalities including cell cycle regulatory genes such as, TP53, RB1, FHIT, DCC and SMAD4. ${ }^{8}$

NEC lesions may be ulcerative and protrude into the lumen. The mass of the tumor often extends to the muscularis layer of the propia or deeper. Necrosis and hemorrhage are common (Figure 10). ${ }^{8}$

Gastric neuroendocrine carcinoma forms a large irregular, sheet or solid trabecular pattern, which is composed of poorly differentiated cells. Large cell type neuroendocrine carcinoma consists of large cells with a vesicular nucleus showing prominent daughter nuclei and a broad eosinophilic cytoplasm (Figure 11). Small cell-type neuroendocrine carcinoma consists of neoplastic cells with narrow cytoplasm, hyperchromatic nucleus without a nucleus, molding nucleus and background necrosis (Figure 12). ${ }^{11}$

Gastric neuroendocrine carcinoma of both large and small cell types was positive for synaptophycin, whereas CgA could be negative or expressed focally. Small cell-type neuroendocrine carcinoma can also be positive for TTF1 and ASH1.11. Neuroendocrine carcinomas often show immunoreactivity against p53 and pansitokeratin (Figure 13).8 Neuroendocrine carcinomas usually have a very high Ki-67 index, diffusely above 50\% (Figure 14). ${ }^{7}$

Most of the NEC are far metastatic at diagnosis and have a very poor prognosis. 28 The survability of NEC averages only a matter of months and most patients with gastric NEC die within 1 year of diagnosis. 8,11

\section{Mixed neuroendocrine-non neuroendocrine neoplasm}

A mixed neuroendocrine-non-neuroendocrine neoplasm is a neoplasm with two populations of neuroendocrine and non-neuroendokine cells. On the gastric, MiNEN is divided into MANEC and MANET. Gastric NEN was found to be $7 \%$ of all gastric NEN (Table 5). 19

\section{Mixed neuroendocrine-adenoma tumor}

A neuroendocrine-non-neuroendocrine mixed neoplasm consisting of a mixture of a welldifferentiated neuroendocrine tumor with an adenoma is defined as MANET. However, the clinicopathology and pathological features of these tumors have not been fully studied. These tumors are more common in 
men than women with a ratio of two to one. Median age at diagnosis was 63 years 20

In WHO 2010, this tumor was classified as MANEC. However, the two components of the mixture can show different morphological features, including adenoma, adenocarcinoma, squamous cell carcinoma and acinar cell carcinoma. To cover the heterogeneity of this mixed tumor, the terminology was changed to "Mixed neuroendocrine-non neuroendocrine neoplasm (MiNEN)".20

Mixed neuroendocrine-adenoma tumors are often asymptomatic, tumors usually detected accidentally on endoscopy are small polypoid masses ranging from 0.3 to $4 \mathrm{~cm} \cdot 19,20$

The adenoma component in MANET mostly shows a tubular pattern of adenoma, some with tubulo-villous appearance and rarely with a villous appearance. Usually also with a picture of dysplasia both low and high degree. The neuroendocrine component consists of the proliferation of well-differentiated (mostly G1) neuroendocrine cells and forming a pattern of small or trabecular nests (Figure 15). The neuroendocrine component is usually localized to the central interior of the polyp. In most cases, NET is confined to the mucosa or muscularis mucosa, but can also infiltrate the submucosa. Mitosis is very rare in MANET. 20

The neuroendocrine component is positive for CgA and synaptophycin. The adenoma component was positive for p53 immunohistochemistry but not the neuroendocrine component. Both components can exhibit immunoreactivity against $\beta$-catenin (Figure 16). Most cases of MANET have a Ki-67 index below $3 \%$, but it can depend more on the degree 20

\section{Adenoneuroendocrine mixed carcinoma}

Adenoneuroendocrine mixed carcinoma is a rare tumor with two differentiations of adenocarcinoma and neuroendocrine, where each component must account for at least $30 \%$ of the tumor mass. In the $2010 \mathrm{WHO}$, MiNEN is classified as MANEC. Because components other than adenocarcinoma are often found in mixed tumors, at WHO 2019, MANEC changed its name to MiNEN and MANEC is a subtype of MiNEN. ${ }^{1}$
Neuroendocrine components can be components that are poorly differentiated, both small cell types and large cell types. ${ }^{21}$

Mixed adenoneuroendocrine carcinoma of the stomach accounts for $20 \%$ of all MANEC in the digestive tract. NEC and MANEC can occur anywhere in the stomach, but usually occur in the antrum and gastric cardiac. MANEC is common in men, with a mean age of 64 years ${ }^{11}$

Adenoneuroendocrine mixture carcinoma has the same chromosomal structural abnormalities as adenocarcinoma, indicating that MANEC has a close relationship with adenocarcinoma. All of the most common disorders in MANEC include genes that regulate the cell cycle, namely TP53, RB1, PTEN, APC, PI3KCA, KRAS and MYC. 22

Mixed adenoneuroendocrine carcinoma often exhibits non-specific symptoms such as heartburn, dysphagia, frequent belching after meals, anorexia and weight loss. Patients also frequently have metastatic symptoms, such as shortness of breath and pleural effusions. On abdominal ultrasound, metastatic nodules can be found in the liver. 22

Mixed adenoneuroendocrine carcinoma has the same mass appearance as adenocarcinoma, often seen as a polypoid or ulcerative mass, with a mean size of 5 $\mathrm{cm}$. The mass often infiltrates the serosa and attaches to the tissue around the stomach. This mass can also be detected using a computed tomography-scan (CTscan) (Figure 17) .21

Adenoneuroendocrine mixed carcinoma is a tumor with adenocarcinoma and neuroendocrine differentiation, where each component must comprise at least $30 \%$ of the tumor mass. Adenocarcinoma components can be cells with mucin cell differentiation, columnar cells with apical mucin vacuoles, paneth cells with coarse eosinophilic granules. NEC components can be small cells or large cells (Figure 18).8,23

The adenocarcinoma component in gastric MANEC can be distinguished by immunohistochemical staining in the form of CEA and not stained with neuroendocrine markers. The components of NEC can be confirmed by neuroendocrine immunohistochemical 
staining such as synaptophycin. The Ki-67 index on MANEC can range from 60 - 90\% (Figure 19)..$^{8}$

The general prognosis of MANEC is still better than NEC. The adenocarcinoma component is a predictive factor associated with a poorer prognosis. Regional lymph node metastases in MANEC are usually frequent.24

Table 1. Criteria for the degree and classification of WHO 2019 NEN in the digestive tract and hepatopancreatobiliary organs. 10,11

\begin{tabular}{|c|c|c|c|c|}
\hline Terminology & Differentiation & Level & $\begin{array}{c}\text { Mitosis rate } \\
\text { (mitosis / } 2 \mathrm{~mm}^{2} \text { ) }\end{array}$ & Ki-67 Index \\
\hline NET, G1 & \multirow{3}{*}{$\begin{array}{l}\text { Good } \\
\text { differentiation }\end{array}$} & Low & $<2$ & $<3 \%$ \\
\hline NET, G2 & & Intermediate & $2-20$ & $3-20 \%$ \\
\hline NET, G3 & & High & $>20$ & $>20 \%$ \\
\hline NEC, small cell type & \multirow{2}{*}{$\begin{array}{l}\text { Poor } \\
\text { differentiation }\end{array}$} & \multirow{2}{*}{ High } & $>20$ & $>20 \%$ \\
\hline NEC, large cell type & & & $>20$ & $>20 \%$ \\
\hline MiNEN & $\begin{array}{l}\text { Good or bad } \\
\text { differentiation }\end{array}$ & Varies & Varies & Varies \\
\hline
\end{tabular}

Table 2. Subtypes of gastric neuroendocrine tumors with the International Classification of Disease for Oncology (ICD-O) code.

\begin{tabular}{lr}
\hline Neuroendocrine tumor $(\mathbf{N E T})$ & $\mathbf{( 8 2 4 0 / 3 )}$ \\
\hline Histamine-producing enterchromaffin-like-cell (ECL-cell) NET & \\
Type 1 ECL-cell NET & $(8242 / 3)$ \\
Type 2 ECL-cell NET & $(8242 / 3)$ \\
Type 3 NET & $(8240 / 3)$ \\
G1 NET & $(8240 / 3)$ \\
G2 NET & $(8249 / 3)$ \\
G3 NET & $(8249 / 3)$ \\
Somastatin-producing D-cell NET & $(8156 / 3)$ \\
Gastrin-producing G-cell NET & $(8153 / 3)$ \\
Serotonin-producing enterochromaffin-cell (EC-cell) NET & $(8156 / 3)$ \\
\hline
\end{tabular}

Table 3. Three types of gastric ECL cell neuroendocrine tumors. ${ }^{7,11}$

\begin{tabular}{|c|l|l|l|l|l|}
\hline Type & \multicolumn{1}{|c|}{$\begin{array}{c}\text { Cells that } \\
\text { proliferate }\end{array}$} & Genetic & \multicolumn{1}{|c|}{$\begin{array}{c}\text { Serum gastrin } \\
\text { levels }\end{array}$} & $\begin{array}{c}\text { Pathogenesis } \\
\text { mechanism }\end{array}$ & $\begin{array}{c}\text { Mucosal } \\
\text { appearance }\end{array}$ \\
\hline 1 & ECL cells & $\begin{array}{l}\text { Can from } \\
\text { mEN1 } \\
\text { mutation }\end{array}$ & $\begin{array}{l}\text { Secondary } \\
\text { hypergastrinemia } \\
\text { (resulting from } \\
\text { achlorhydia) }\end{array}$ & $\begin{array}{l}\text { Autoimmune } \\
\text { gastritis }\end{array}$ & $\begin{array}{l}\text { Atrophic } \\
\text { gastritis }\end{array}$ \\
\hline 2 & ECL cells & $\begin{array}{l}\text { MEN1 } \\
\text { mutations }\end{array}$ & $\begin{array}{l}\text { Primary } \\
\text { hypergastrinemia } \\
\text { due to excess } \\
\text { gastrin secretion) }\end{array}$ & ZES, MEN1 & $\begin{array}{l}\text { Hyperplasia or } \\
\text { hypertrophy of } \\
\text { parietal cells }\end{array}$ \\
\hline
\end{tabular}




\begin{tabular}{|c|l|l|l|l|l|}
\hline 3 & Different types of cells & Sporadic & $\begin{array}{l}\text { Do not have } \\
\text { hypergastrinemia }\end{array}$ & Unknown & Not specific \\
\hline
\end{tabular}

Table 4. Subtypes of gastric neuroendocrine carcinoma coded ICD-O.11

\begin{tabular}{ll}
\hline Neuroendocrine carcinoma (NEC) & $\mathbf{( 8 2 4 6 / 3 )}$ \\
\hline Small cell neuroendocrine carcinoma (SCNEC) & $(8041 / 3)$ \\
Large cell neuroendocrine carcinoma (LCNEC) & $(8013 / 3)$ \\
\hline
\end{tabular}

Table 5. Subtypes of mixed neuroendocrine-non-neuroendocrine gastric neoplasms coded ICD-O.11

\begin{tabular}{ll}
\hline Mixed neuroendocrine-non neuroendocrine neoplasm (MiNEN) & $(8154 / 3)$ \\
\hline Mixed adenocarcinoma-NEC, or mixed adenoneuroendocrine carcinoma (MANEC) & $(8244 / 3)$ \\
Mixed adenocarcinoma-NET & $(8244 / 3)$ \\
\hline
\end{tabular}
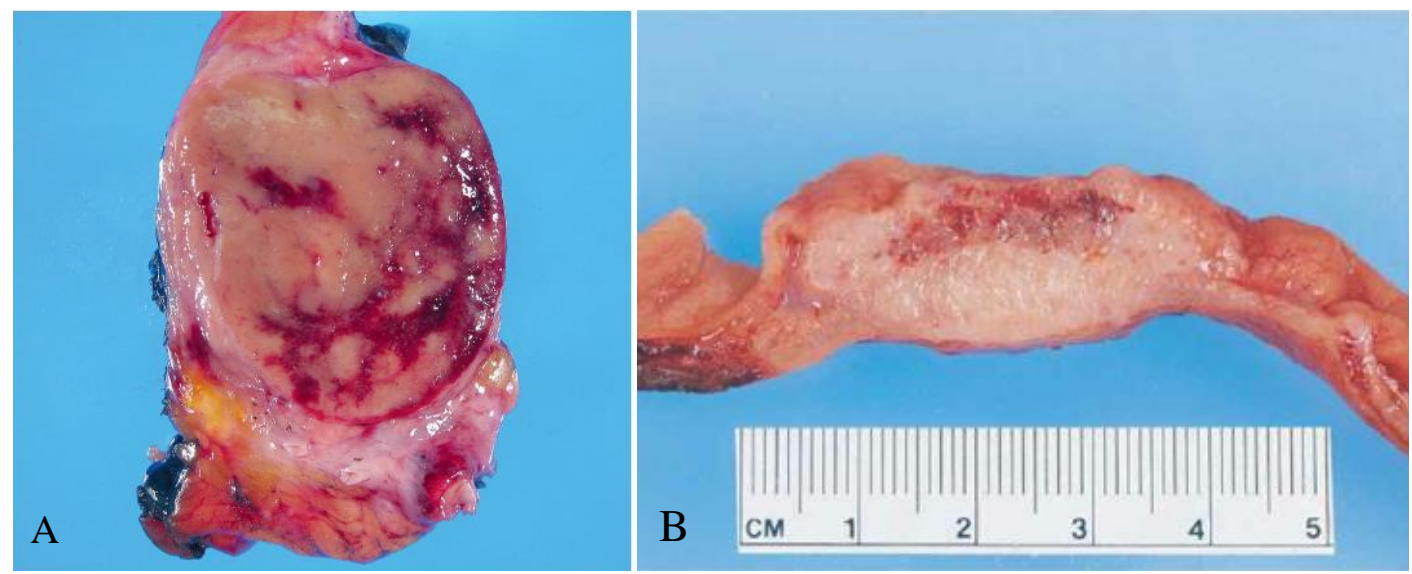

Figure 1. Neuroendocrine tumor of ECL cells. A) The tumor is usually well-defined, has a smooth surface with a rubbery consistency. Bleeding foci can be seen. $\left.{ }^{7} \mathrm{~B}\right)$ Cross section shows that the tumor has extended to the gastric wall.8

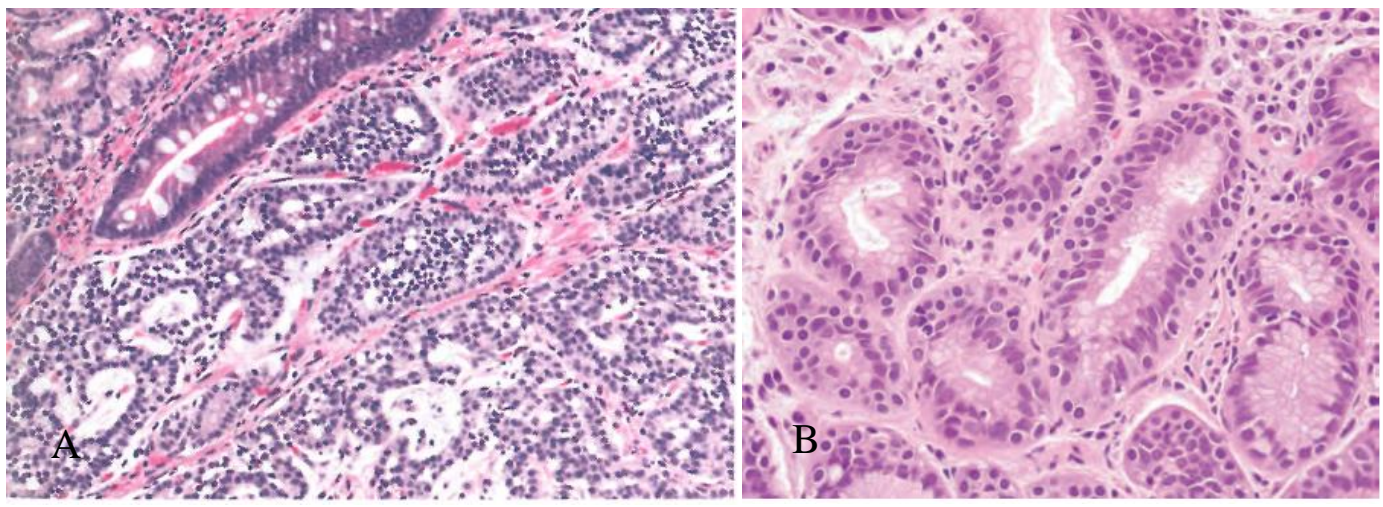



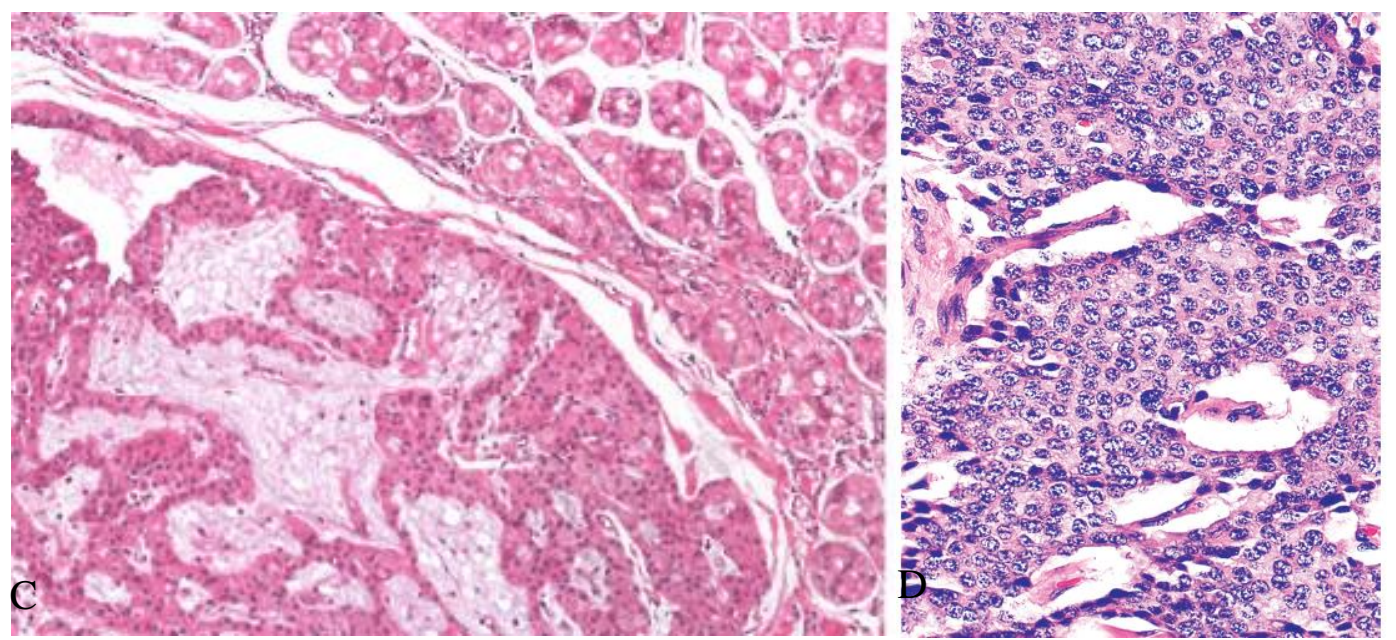

Figure 2. Neuroendocrine tumors of ECL type 1 and 2 cells. A) Type 1 originates from a background with atrophic gastritis characterized by intestinal and pseudopilorus metaplasia (upper left corner), the mass of the tumor forms a microlobular structure without necrosis with a monomorphic nucleus and non-nucleus 11 B) The small clear cells surrounding the metaplasia glands in ECL type 1.13 cells. C) The peritumoral mucosa of type 2 ECL cells is usually not atrophy. D) Neuroendocrine tumor cells type 1 and 2 ECL cells are characterized by a round nucleus, monomorphic and salt-and-pepper chromatin.


Figure 3. NET ECL type 3 cells. A) Mass of tumor with a predominantly solid pattern that extends to a deeper layer in the gastric wall. B) Staining with CgA shows a clearer picture. ${ }^{13}$
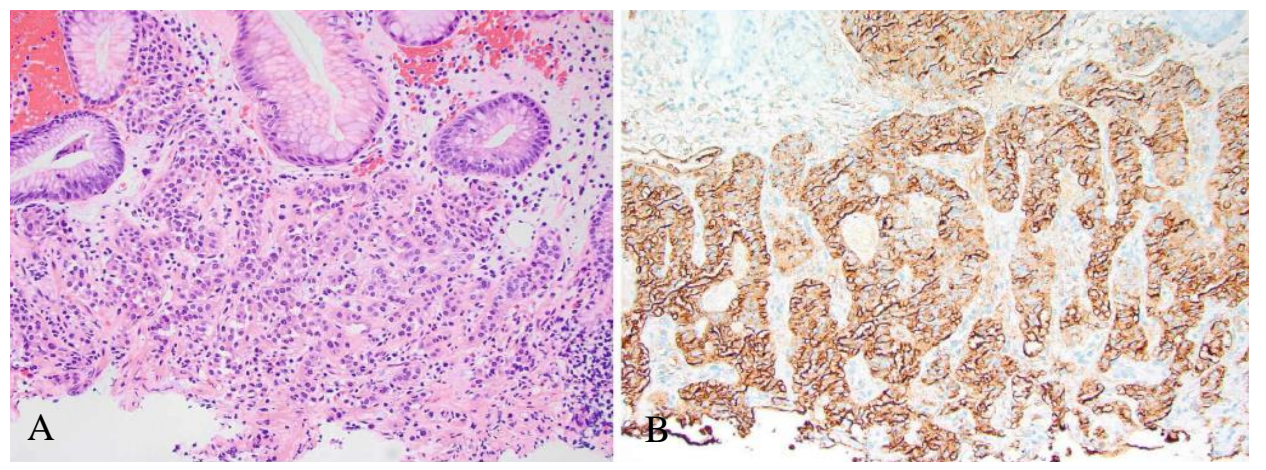

Figure 4. Gastric NET immunohistochemical staining. A) NET originating from autoimmune gastritis on HE stain. B) Positive synaptophycin staining against tumor cells. 8 




Figure 5. Ki-67 proliferation index in neuroendocrine tumors. A) NET G1 with Ki-67 below 1\%. B) NET G2 with Ki67 8.5\%. C) NET G3 with Ki-67 90\%. 8



Figure 6. Endoscopy of G-cell NETs. A small, multiple, polypoid mass with smooth surface and a central depression is shown. 

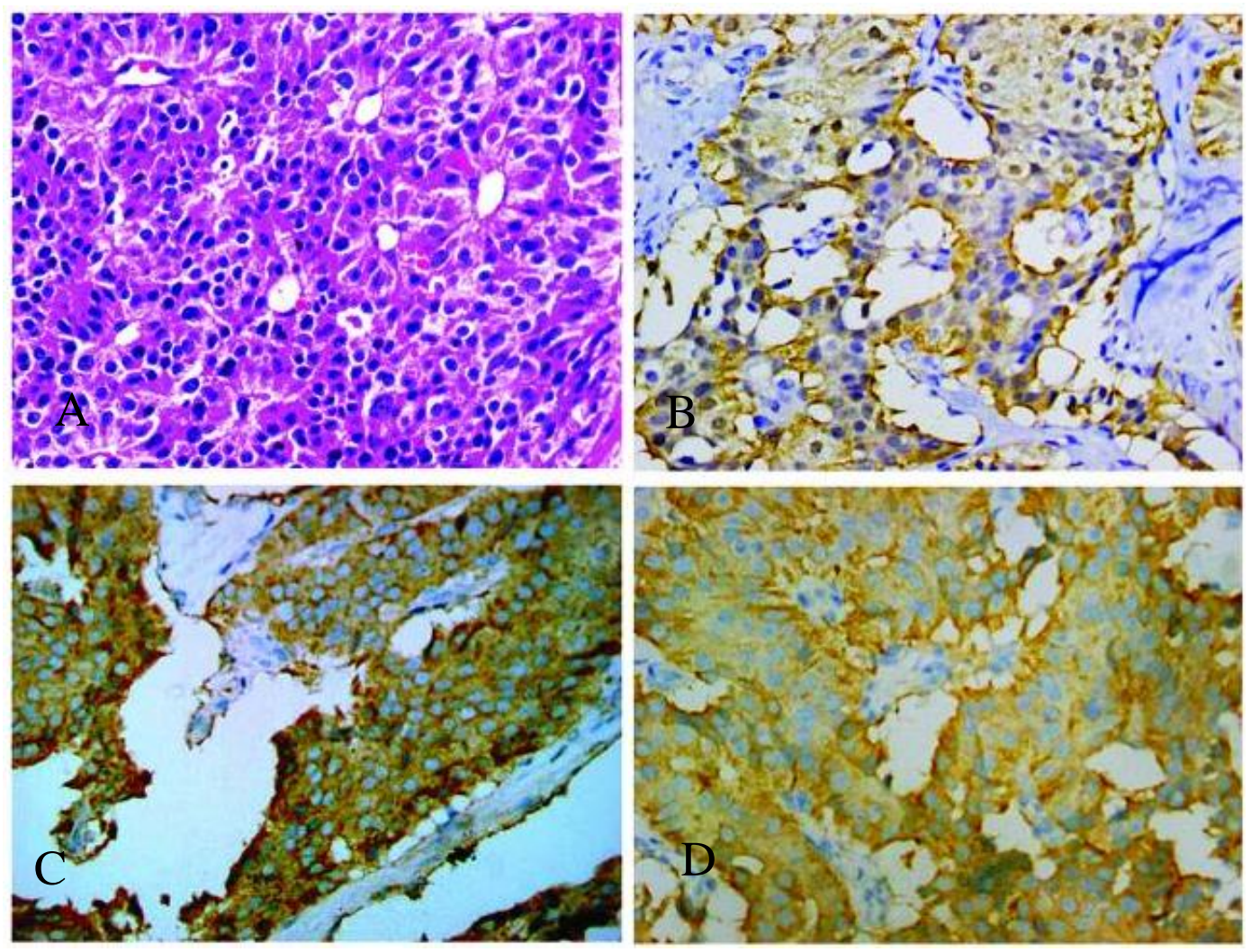

Figure 7. Microscopic image of G cell NETs. A) Haematoxylin and eosin staining shows a trabecular pattern. B) Positive with gastrin immunohistochemical staining. C) Positive with CgA. D) positive with synaptophycin. ${ }^{16}$

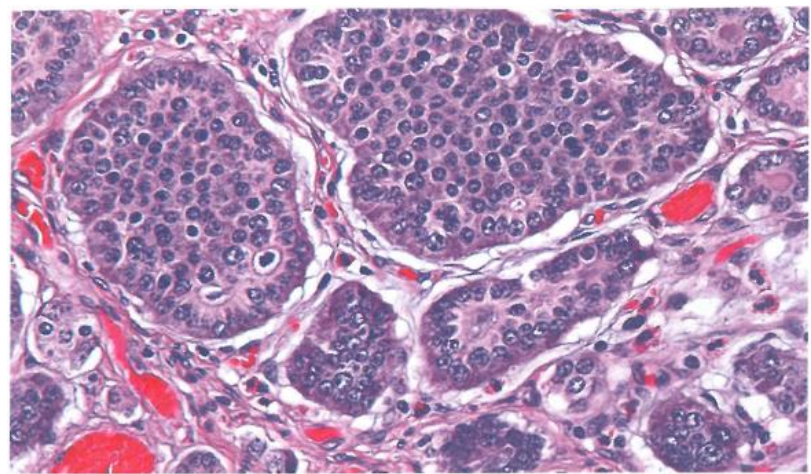

Figure 8. Microscopic view of EC cell NETs. The tumor forms a round nest with peripheral core palisading. ${ }^{11}$ 


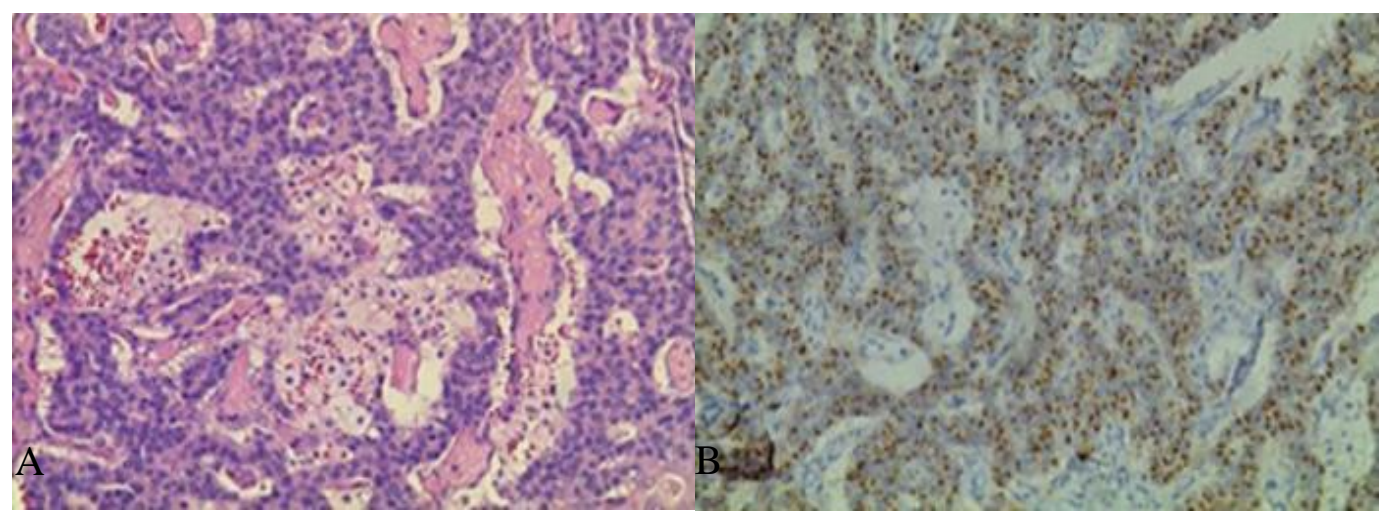

Figure 9. Microscopic image of D-cell NET. A) It shows that the tumor mass forms a trabecular pattern on HE staining. B) The tumor cells are strongly positive for somatostatin. ${ }^{18}$

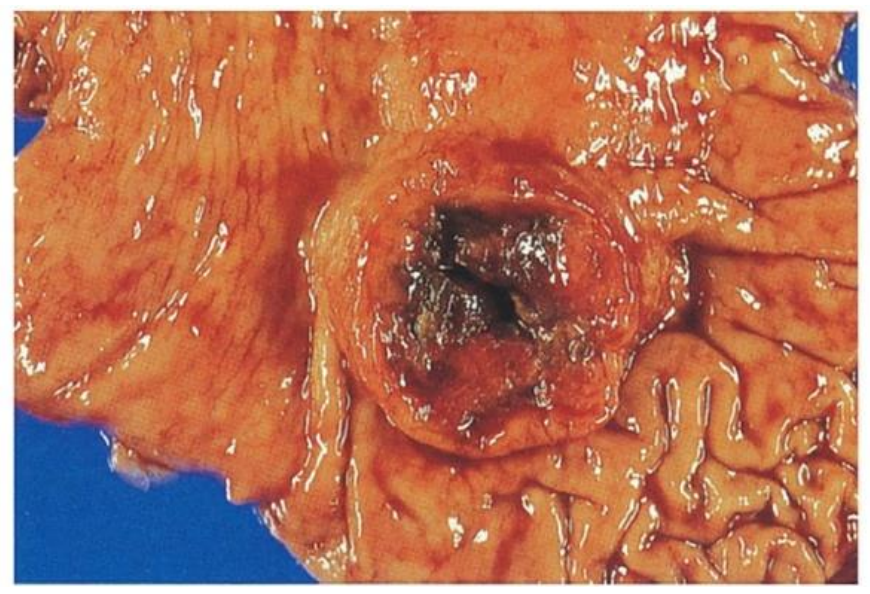

Figure 10. Macroscopic overview of gastric NEC. Polypoid shaped tumor with ulcerated surface, necrosis and bleeding. 8


Figure 11. Microscopic image of gastric LCNEC. A) The tumor forms a sheet consisting of cells with a large nucleus, vesicular, prominent nucleus and many mitoses. B) This tumor mass has a large trabecular structure ${ }^{13}$ 


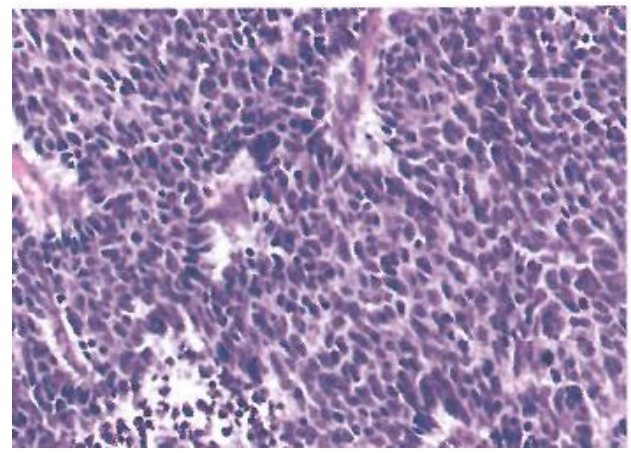

Figure 12. Microscopic view of a gastric SCNEC. The tumor mass forms a solid sheet structure consisting of small cells with a hyperchromatic nucleus, the nucleus is not visible 11

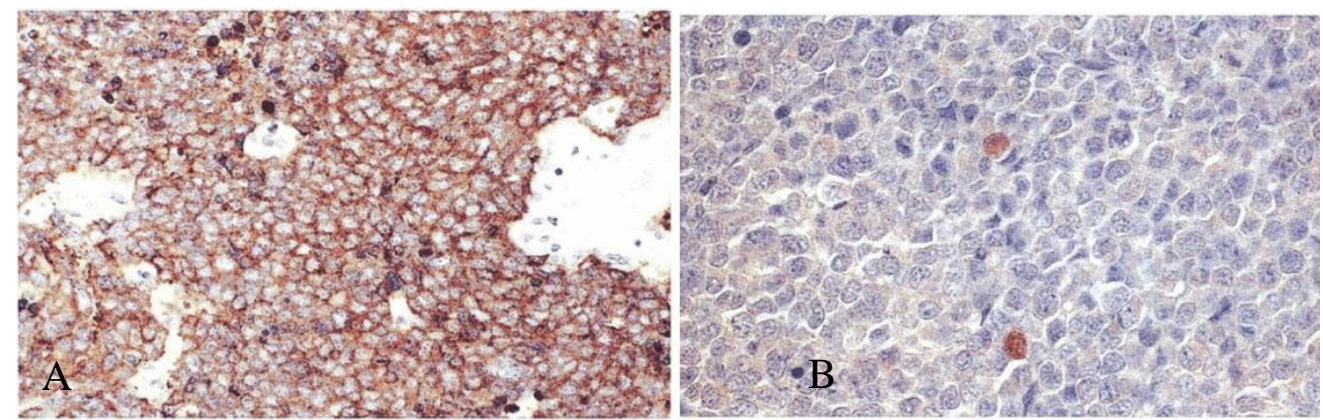

Figure 13. Immunohistochemistry in gastric SCNEC. A) Synaptophycin is always strong positive for NEC. B) Immunohistochemistry of $\mathrm{CgA}$ is often focal positive. 8



Figure 14. LCNEC gastric immunohistochemistry. A) Large type NEC forms a sheet pattern on routine coloring. B) Synaptophycin immunohistochemical staining. ${ }^{8}$ 

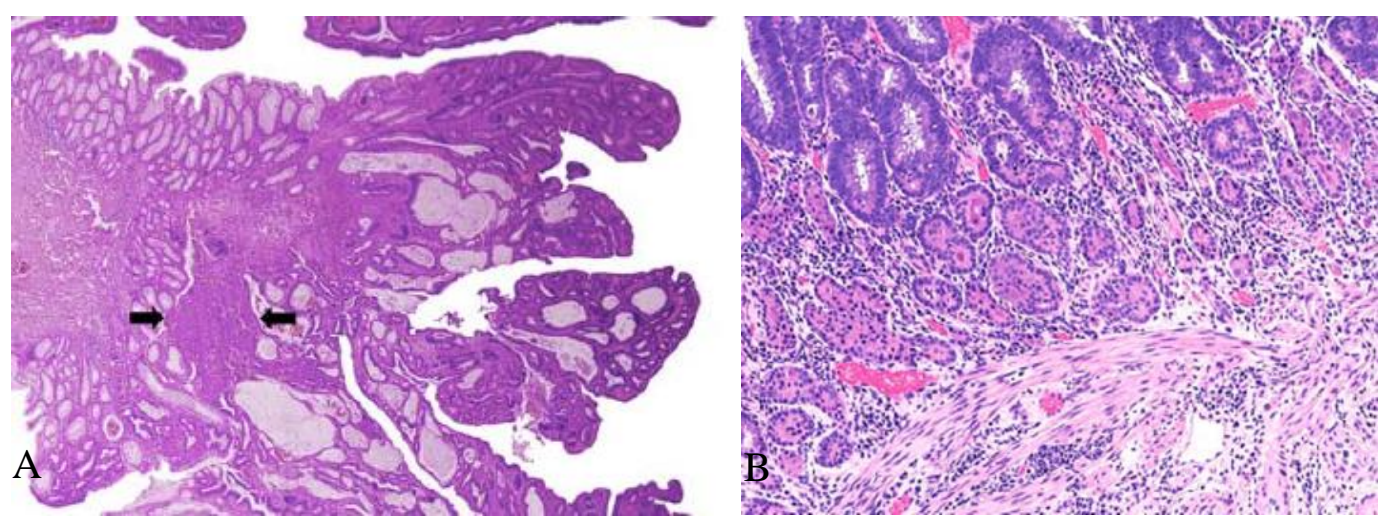

Figure 15. Microscopic overview of MANET. A) Small enlargement indicates localization of the neuroendocrine component of MANET in the central part of the polyp. B) Large enlargement indicates the proliferation of well differentiated neuroendocrine cells forming a nesting pattern. ${ }^{20}$



Figure 16. Immunohistochemistry in MANET. A) The neuroendocrine tumor component of MANET is positive for synaptophycin. B) Strong positive $\beta$-catenin immunohistochemistry in the nucleus and cytoplasm of the neuroendocrine component, focal-focal to the adenoma component. 20

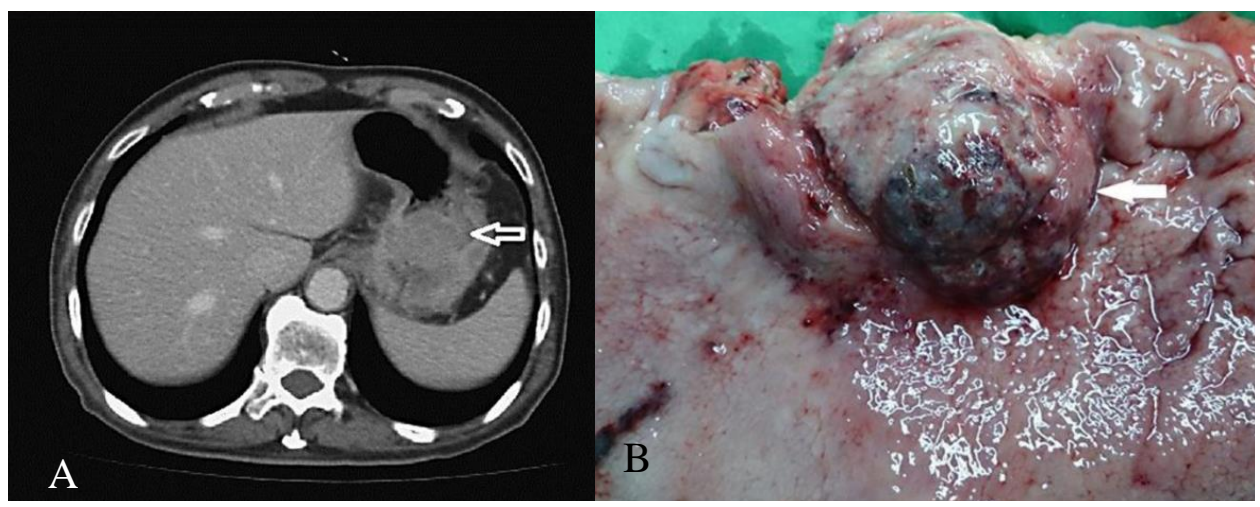

Figure 17. CT-Scan and macroscopic view of MANEC. A) Focal polypoid lesion of the stomach with approximate lymph node enlargement. B) The mass of the tumor protrudes on the posterior wall of the stomach with thickening of the wall. 21 


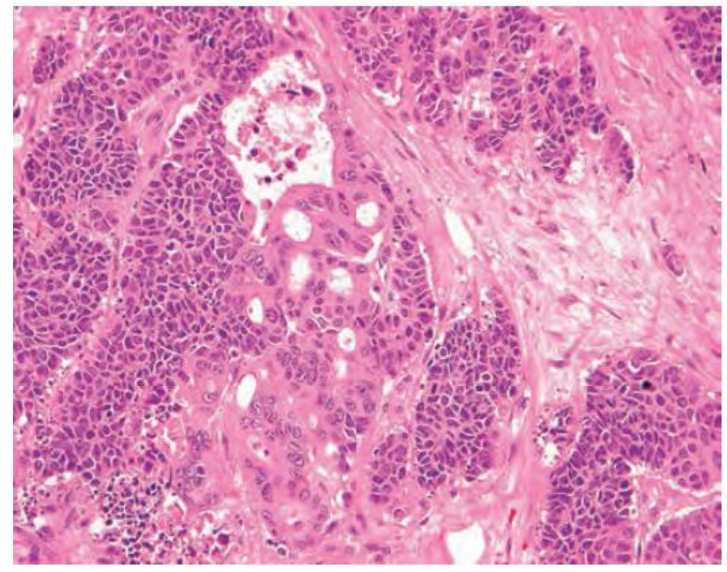

Figure 18. MANEC microscopic view of the gastrointestinal tract. There is a differentiation component of adenocarcinoma in the middle part with a component of small cell neuroendocrine carcinoma. ${ }^{13}$

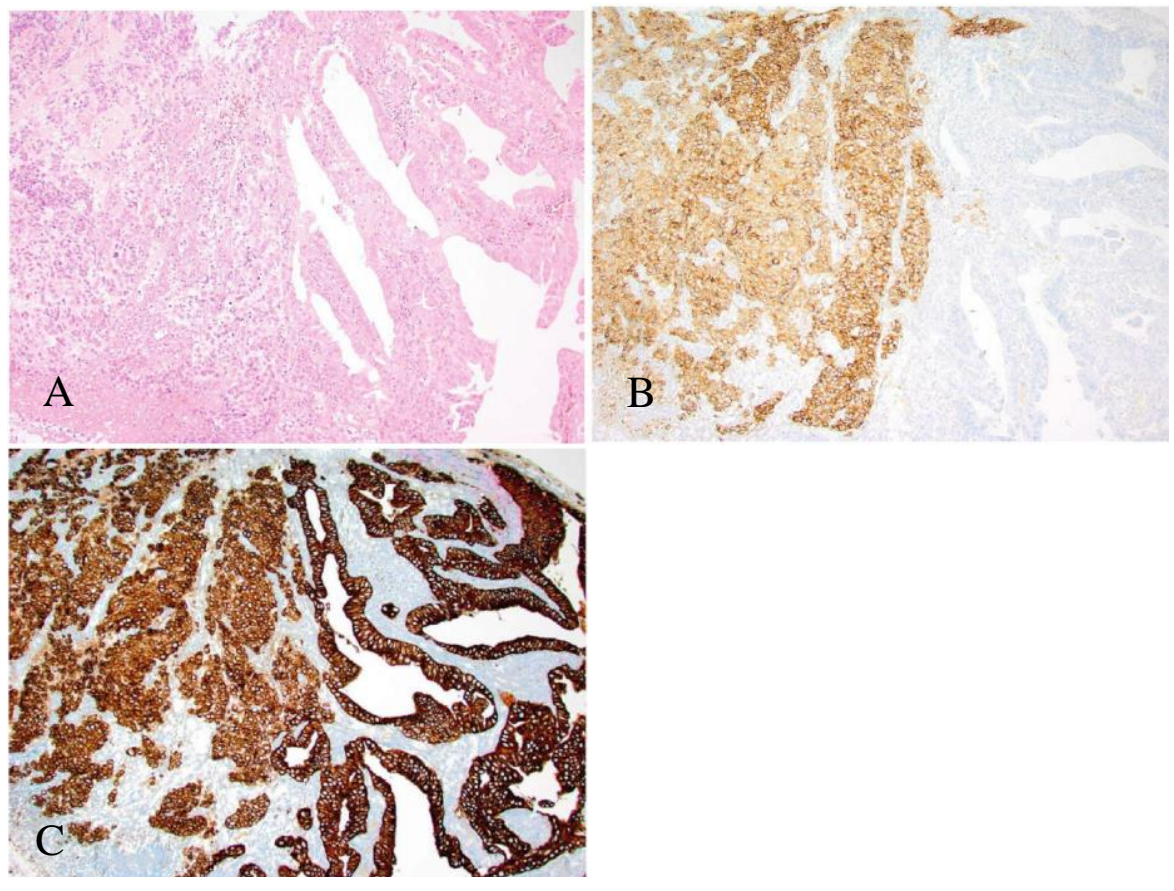

Figure 19. Immunohistochemistry at MANEC. A) Neuroendocrine carcinoma (left) with adenocarcinoma (right) on routine stain. B) Synaptophycin immunohistochemistry positive for NEC, negative for adenocarcinoma. C) Pansitokeratin staining is positive for both components. ${ }^{8}$

\section{Conclusion}

Neuroendocrine neoplasms (NEN) can occur in all epithelial organs of the body with various etiologies, clinical features, morphology, genetic findings and prognosis. Changes in terminology, classification, grade and subtypes of gastric neuroendocrine neoplasms at WHO 2019 indicate that these tumor types have different effects on pathogenesis, morphological features, therapy and prognosis, so that the characteristics of these tumors need to be distinguished. In addition, there are also types of tumors that are not fully known, so further research is needed. 


\section{Referensi}

1. Solcia E, Arnold R, Capella C, Klimstra DS, Kloppel G, Komminoth P, et al. WHO classification of tumours of the digestive system. $4^{\text {th }}$ ed. Lyon: International Agency for Research on Cancer (IARC); 2010. p. 64-8.

2. Li TT, Qiu F, Qian ZR, Wan J, Qi XK, Wu BY. Classification, clinicopathologic features and treatment of gastric neuroendocrine tumors. World J Gastroenterol 2014;20(1):118-25.

3. Dias AR, Azevedo BC, Alban LB, Yagi OK, Ramos $\mathrm{MF}$, Jacob $\mathrm{CE}$, et al. Gastric neuroendocrine tumor : review and update. ABCD Arq Bras Cir Dig 2017;30(2):150-4.

4. Cheung KS, Leung WK. Long-term use of protonpump inhibitors and risk of gastric cancer: a review of the current evidence. Therap Adv Gastroenterol 2019;12:1-11.

5. Waldum HL, Fossmark R. Proton pump inhibitors and gastric cancer: a long expected side effect finally reported also in man. Gut 2018;67:199-200

6. Joo MK, Park JJ, Chun HJ. Proton pump inhibitor: the dual role in gastric cancer. World $\mathrm{J}$ Gastroenterol 2019;25(17):2058-70.

7. Odze RD, Glodblum JR, Adsay NV, Klimstra DS. Odze and goldblum surgical pathology of the gastrointestinal tract, liver, billiary tract, and pancreas. 3 rd ed. Philadelphia: Elsevier Saunders; 2015. p. 803-22.

8. Cockburn A, Rege TA, Noffsinger AE. FenoglioPreiser's gastrointestinal pathology. 4th ed. Philadelphia: Wolters Kluwer; 2017. p. 3300512.

9. Waldum HL, Sordal OF, Mjones PG. The enterochromaffin-like (ECL) cell central in gastric physiology and pathology. Int J Mol Sci 2019;20(10):1-11.

10.Wiley J. The 2019 WHO classification of tumours of the digestive system. Histopathol 2020;76:182-8.
11. Cree IA, La Rosa S, Rindi G, Solcia E, Tang LH. WHO classification of tumours of the digestive system. $5^{\text {th }}$ ed. Lyon: International Agency for Research on Cancer (IARC); 2019. p.105-10.

12.Mun JY, Chin HM, Jun KH. A 13-year experience with gastric neuroendocrine tumors: a single institute study. KJCO 2018;14:8-14.

13. Riddell R, Jain D, Bernstein CN, Guha S. Lewin, Winstein and Riddell's gastrointestinal pathology and its clinical implications. $2^{\text {nd }}$ ed. Philadelphia: Wolters Kluwer; 2014. p. 190-226.

14. Yang $Z$, Wang WH, Lu JF, Pan G, Pan Z, Chen Q, Liu WY, et al. Gastric neuroendocrine tumors: incidence, prognosis and recent trend toward improved survival. Cell Physiol Biochem 2018;45:389-96.

15.Barbosa A, Gomes F, Fonseca L, Maia T, Almeida J. De novo gastrinoma: a case report. GE Port J Gastroenterol 2020;27:192-6.

16.Zhang WD, Liu DR, Wang P, Zhao JG, Wang ZF, Chen L. Clinical treatment of gastrinoma: a case report and review of the literature. Oncol Lett 2016;11:3433-7.

17.Sasaki K. Duodenal gastrinoma associated with multiple endocrine neoplasia type 1 (MEN1) detected by esophagogastroduodenoscopy, which was buried under ulcer. J Gastrointest Dig Syst 2016;6(2):1-5.

18.Zhang W, Yang G, Li H, Wang H, Jin Y, Chen H, et al. Hypoglycemia as the onset manifestation of somatostatinoma: a case report and review of the literature. Int $\mathrm{J}$ Clin Exp Med 2017;10(11):15666-71.

19.Mestier L, Cros J, Neuzillet C, Hentic O, Egal A, Muller $\mathrm{N}$, et al. Digestive system mixed neuroendocrine-non-neuroendocrine neoplasms. Neuroendocrinol 2017;105:412-25.

20.La Rosa S, Uccella S, Molinari F, Savio A, Mete O, Vanoli A. Mixed adenoma well-differentiated neuroendocrine tumor (MANET) of the digestive system. Am J Surg Pathol 2018;00(0):1-10. 
21.Kwok CM. Mixed adenoneuroendocrine carcinoma of the stomach. Case Rep Gastroenterol 2015;9(2):241-5.

22.Frizziero M, Chakrabarty B, Nagy B, Lamarca A, Hubner RA, Valle JW. Mixed neuroendocrine non-neuroendocrine neoplasms: a systematic review of a controversial and underestimated diagnosis. J Clin Med 2020;9:1-23.

23. Min BH, Hong M, Lee JH, Rhee PL, Sohn TS, Kim $\mathrm{S}$, et al. Clinicopathological features and outcome of type 3 gastric neuroendocrine tumours. Br J Surg 2018;105(11):1480-6.

24.Oneda E, Liserre B, Bianchi D, Rota L, Savelli G, Zorzi F, et al. Diagnosis of mixed adenoneuroendocrine carcinoma (MANEC) after neoadjuvant chemoterapy for pancreatic and gastric adenocarcinoma: two case reports and a review of the literature. Case Rep Oncol 2019;12:434-42. 